\title{
Saberes necessários aos professores para promover a inclusão de alunos com necessidades Educacionais Especiais
}

Gislaine Semcovici Nozi* Celia Regina Vitaliano**

\section{Resumo}

O presente trabalho tem como objetivo identificar, por meio de revisão da literatura da área especializada, os saberes necessários aos professores para promover a inclusão de alunos com necessidades educacionais especiais (NEE) no ensino regular. Para tanto, realizou-se um levantamento bibliográfico junto a sete periódicos, dez capítulos de livros e três dissertações da área de Educação e Educação Especial, produzidos entre os anos de 2005 a 2009. Os resultados indicam a necessidade de conhecimentos teóricos, conceituais e metodológicos específicos para incluir tais alunos em classe comum. Os dados obtidos foram organizados em categorias. Dentre os saberes indicados pelos autores consultados, destacam-se os conhecimentos relacionados a métodos e técnicas cooperativas e colaborativas para favorecer a inclusão de alunos com NEE; à caracterização desses alunos; aos procedimentos didático-pedagógicos para favorecer sua inclusão; à legislação e fundamentos da educação inclusiva; ao papel da educação especial na educação inclusiva; às barreiras sociais que dificultam o processo de inclusão dos alunos com NEE, dentre outros. Consideramos que os resultados desta pesquisa podem contribuir para subsidiar a organização dos conteúdos a serem contemplados no processo de formação de professores inicial, continuada e/ou em serviço para favorecer o processo de inclusão de alunos com NEE.

Palavras-chave: Educação inclusiva; Saberes docentes; Formação de professores.

\section{Teacher's needed knowledge to promote the inclusion of students with Educational Special needs}

\begin{abstract}
The main objective of the following paper is to identify, by a revision from the specialized area literature, the needed knowledge required by teachers to promote the inclusion of students with special educational needs (SEN) in regular education. To achieve this goal, was prepared a bibliographic survey from seven magazines, ten books' chapters and three dissertations from Education and special education area, produced between 2005 and 2009. The achieved data was

\footnotetext{
* Mestranda no Programa de mestrado em Educação da Universidade estadual de Londrina, Paraná, Brasil.

** Professora doutora do Departamento de Educação e do Programa de Mestrado em Educação da Universidade Estadual de Londrina. Paraná, Brasil.
} 
organized into categories. The results indicate the necessity of specific theoretical, conceptual and methodological knowledge to include students in an ordinary classroom. Between all knowledge indicated by the checked authors, is pointed out the understanding related to corporative and collaborative method and technique to favor the inclusion of students with SEN; the characteristics of these students, to the procedure didactic-pedagogic to favor the inclusion; to the legislation and fundamentals from inclusive education; to the social barriers that difficult the inclusion process from students with SEN, among others. We consider that this research result can contribute to subsidize the content organization which will be contemplated in the teaching training and continued formation process and/or teachers who are working to favor the inclusion process for SEN students.

Keywords: Inclusive education; Teaching Knowledge; Teacher's formation.

\section{Introdução}

Falar sobre a educação inclusiva nos remete a pensar qual é a concepção de educação e do papel da escola no mundo atual. Compreendemos que a educação escolar deve propiciar aos indivíduos o desenvolvimento cognitivo, social, psicológico, afetivo, enfim, deve prepará-los para atuarem de forma plena na sociedade. Diferentemente do que nos conta a história da educação brasileira, compreendemos que a educação escolar não é privilégio de alguns (SAVIANI, 2000). Assim como ressaltam diversas leis de nosso país, a educação é um direito de todos, independentemente de raça, cor, religião, condição econômica etc., uma vez que "todos são capazes e têm o direito de aprender" (SALGADO, 2006, p. 60).

Compartilhamos com a ideia de Glat et al. (2006) de que "o professor, sozinho, não faz a inclusão, a política, sozinha, não faz a inclusão", faz-se necessária uma série de ações subsequentes às políticas inclusivas para que a inclusão de alunos com necessidades educacionais especiais (NEE) ocorra no sistema regular de ensino e sob condições adequadas.

Os resultados das pesquisas mais recentes da área de Educação Especial na perspectiva inclusiva mostram que não basta apenas matricular uma criança deficiente numa classe comum do ensino regular. A simples inserção do aluno deficiente, determinada por lei, não garante que o aluno seja bem acolhido pelo professor e pelos colegas da classe, muito menos que o ensino e 0 atendimento tenham qualidade e sejam adequados às suas particularidades $\mathrm{e}$ necessidades especiais (OMOTE et al., 2005).

A maioria das publicações referentes à educação inclusiva aponta que a efetivação das políticas educacionais inclusivas têm se dado de modo a evidenciar que os professores, de modo geral, de todos os níveis de ensino, vêm enfrentando dificuldades para promover a aprendizagem acadêmica e a participação social dos alunos com NEE (ROSSETTO, 2009; RAMOS, 2009). 
Consideramos que "a forma como o professor atua irá influenciar e, quem sabe, determinar o alcance ou não dos objetivos de ensino e dos ideais de inclusão da educação" conforme aponta Salgado (2006, p. 66). Este pressuposto é corroborado por vários pesquisadores da área, tais como: Ferreira (2006), Glat et al. (2006), Pletsch (2009), Rodrigues (2008a), Vitaliano (2007; 2010), entre outros, os quais afirmam que uma das condições determinantes para a efetivação do processo de inclusão é a formação dos professores.

Levando em consideração esta situação, a presente pesquisa propôs-se investigar os saberes necessários aos professores para favorecer o processo de inclusão de alunos com NEE, tomando como base as indicações apresentadas pela literatura nacional especializada da área.

\section{Saberes docentes}

Discutir sobre os saberes necessários aos professores para incluir alunos com NEE vai ao encontro da afirmação de André e Mackenzie, (s. d., p. 6) de que "[...] o trabalho docente requer um conjunto de saberes que não são aprendidos espontaneamente" e de que professores são profissionais da educação, portanto, [...] "tem na docência e no trabalho pedagógico a sua particularidade e especificidade" (FREITAS, 2002, p. 139). Acrescido do fato de que há saberes próprios que abrangem tanto os conhecimentos disciplinares como os conhecimentos pedagógicos.

Sob esta perspectiva, podemos afirmar que "o 'saber profissional' dos professores é constituído não por um 'saber específico', mas por vários 'saberes' de diferentes matizes, de diferentes origens, aí incluídos, também, o 'saber-fazer' e o saber da experiência" (CUNHA, 2003, p. 6).

Segundo Nunes (2001), as pesquisas relacionadas aos saberes docentes expandiram-se a partir da década de 1990, motivadas pelo movimento de profissionalização do ensino o que, consequentemente, trouxe mudanças sobre concepções relacionadas aos saberes dos professores, que passaram a buscar formas de legitimar os conhecimentos de sua profissão.

Alves (2007) e Nunes (2001) comentam que os estudos realizados nos últimos vinte anos sobre os saberes docentes têm apontado que a formação do professor não implica exclusivamente no fornecimento de boas teorias técnicas e metodológicas para o ensino, já que o professor, em sua atuação pedagógica, não utiliza apenas conhecimentos científicos, há uma gama de saberes - além daqueles do campo propriamente pedagógico e curricular - que é de ordem histórica, política, social, cultural, pessoal, afetiva etc., que influenciam, constroem e reconstroem os saberes dos professores valendo-se da prática cotidiana. 
Segundo Tardif (2000), os saberes profissionais dos professores apresentam as seguintes características, que são: temporais, plurais, heterogêneos, personalizados e situados, além disso, carregam as marcas dos seres humanos e são constituídos pelos conhecimentos, habilidades ou aptidões e atitudes.

Destacamos que este artigo é um recorte de um trabalho mais amplo intitulado Saberes necessários aos professores do ensino regular para promover a inclusão de alunos com necessidades educacionais especiais (NOZI, 2010), o qual consistiu em um estudo bibliográfico que analisou os saberes (conhecimentos teóricos e metodológicos), as habilidades (saber fazer) e as atitudes necessários aos professores do ensino regular para promover a inclusão de alunos com NEE. Especificamente neste artigo apresentaremos algumas análises derivadas dessa pesquisa concernente aos saberes referentes aos conhecimentos conceituais, teóricos e metodológicos necessários aos professores do ensino regular para promover a inclusão de alunos com NEE. Tal objetivo foi organizado tomando como base as indicações de Rodrigues (2008b, p.12). Para ele o processo de formação dos professores envolve três dimensões: "os saberes, as competências e as atitudes" sendo que os saberes se caracterizam como:

[...] conjunto de conhecimentos de índole mais teórica que fundamenta as opções de intervenção. Estes conhecimentos vão desde aspectos mais diretamente teóricos, tais como o contacto com o pensamento e a teorização de diferentes autores, até (e sobretudo) trabalhos de investigação feitos em contextos reais que possam fundamentar a adoção de determinadas opções metodológicas.

\section{Método}

Este estudo foi realizado por meio de um levantamento bibliográfico junto aos periódicos brasileiros indexados no Scielo, especialmente na Revista Brasileira de Educação Especial, na Revista Educação Especial, além de outros periódicos que publicam artigos da área da educação, tais como: Revista Centro de Educação, Educação \& Sociedade, Paidéia, Educar em Revista e Democratizar, nas edições publicadas entre os anos de 2005 a 2009, período delimitado para coleta dos dados.

Iniciamos a coleta de dados mediante uma busca sistematizada no site do Scielo, no índice de assuntos, por artigos que tinham como palavraschave, em diferentes combinações: educação inclusiva, inclusão, inclusão escolar, formação de professores e práticas docentes. Identificamos a partir dessa busca, um total de 68 artigos publicados nas revistas supracitadas. 
Na sequência, realizamos a leitura dos resumos e, quando necessário, a leitura do texto integral de todos os artigos selecionados para identificarmos se estes traziam, em suas análises e discussões, sugestões com relação à formação de professores para a inclusão dos alunos com NEE. Para tal, buscamos identificar nos textos frases como: "os professores devem", "os professores precisam", "os professores têm". Consideramos que estas frases davam indícios dos saberes necessários aos professores para promoverem a inclusão de alunos com NEE. Tendo como base este critério, foram selecionados 37 artigos.

As frases utilizadas como critério de seleção dos dados para análise foram organizadas com base nas experiências de pesquisas e discussões referentes ao tema formação de professores para inclusão de alunos com NEE, desenvolvidas junto ao grupo de pesquisa: Educação para Inclusão da Universidade Estadual de Londrina, grupo ao qual, as autoras do presente artigo são vinculadas, bem como os resultados das pesquisas realizadas por Vitaliano (2002, 2007, 2010).

Além disso, também fizeram parte dos dados analisados dez capítulos de livros e três dissertações de mestrado. Estes textos compuseram o corpus da pesquisa, em razão de que ao serem lidos para a elaboração do referencial teórico verificamos que apresentavam indicações importantes sobre os saberes necessários ao professor para favorecer a inclusão dos alunos com NEE, totalizando um corpus de 50 trabalhos. Tais livros, bem como uma das dissertações de mestrado foram identificados no acervo da biblioteca da Universidade Estadual de Londrina. As outras duas dissertações de mestrado foram indicadas por membros do referido grupo de pesquisa.

Após a leitura dos 50 trabalhos selecionados, identificamos em 24 deles, frases referentes a conhecimentos teóricos, conceituais e metodológicos que os professores deveriam saber para promover a inclusão de alunos com NEE. Essas frases foram recortadas dos textos, levando-se em consideração o tema como unidade de registro, desta forma cada autor poderia ser citado em mais de uma categoria.

O material coletado foi organizado em categorias, seguindo as orientações de Bardin (2009, p. 44), tendo em vista que o processo de análise dos textos se constituiu em uma análise de conteúdos, conceituada pela referida autora como:

\footnotetext{
Um conjunto de técnicas de análise das comunicações visando obter por procedimentos sistemáticos e objetivos de descrição do conteúdo das mensagens indicadores (quantitativos ou não) que permitam a inferência de conhecimentos relativos às condições de produção/ recepção (variáveis inferidas) destas mensagens.
} 
Orientados pelos objetivos deste estudo, organizamos os dados coletados em um tema denominado: "Saberes necessários para o professor promover a inclusão de alunos com NEE". Para tanto, tomamos por base, como anteriormente citado, a classificação proposta por Rodrigues (2008b) em relação às dimensões de conhecimentos necessárias ao professor para favorecer a inclusão de alunos com NEE.

Tendo em vista que os saberes identificados nos textos foram diversos, organizamos os dados em sete categorias.

\title{
Resultados e discussão
}

\section{Saberes necessários para o professor promover a inclusão de alunos com NEE}

Considerando o objetivo deste artigo, a seguir apresentamos os dados obtidos organizados em categorias de acordo com os aspectos abordados e a frequência identificada nos textos analisados.

\section{colaborativo}

1 - Conhecer métodos e técnicas cooperativas e o ensino

Encontramos quatorze autores que defendem ser importante que o professor do ensino regular conheça e implemente métodos e técnicas colaborativas e o ensino colaborativo nas escolas inclusivas, bem como estabeleçam parcerias com outros profissionais envolvidos na educação inclusiva, com os pais dos alunos com NEE e com a comunidade escolar de modo geral.

Peterson (2006) indica a necessidade de os professores da rede regular receberem capacitação em serviço sobre como trabalhar com alunos com deficiência por meio de métodos e técnicas colaborativas.

\begin{abstract}
Em relação à preparação de professores, os programas de inclusão não podem ser bem sucedidos em escolas públicas se ambos, professores de educação geral e especial não forem capacitados para implementar programas de ensino colaborativo e inclusivo na educação geral para alunos com deficiência. (PETERSON, 2006, p. 8)
\end{abstract}

A autora destaca ainda que, para haver o aprendizado de técnicas inclusivas e colaborativas, os cursos de formação de professores devem projetar em suas ementas conteúdos referentes ao ensino colaborativo.

Para Glat et al. (2006, p. 4), dentre as competências que os professores devem desenvolver na formação inicial e depois aperfeiçoarem na formação continuada, inclui " [...] uma habilidade para atuar como articulador e mediador, e 
provavelmente construtor, de relações de aproximação entre escola, famílias e comunidades".

O estudo feito por Sant' Ana (2005, p. 228) aponta que, para ocorrer o sucesso da atuação do professor em classes inclusivas, faz-se necessário "[...] o estímulo à participação de pais e da comunidade nessa nova realidade social e educacional".

Considerando estas indicações, podemos concordar com as palavras de Salgado (2006, p. 62), que é "[...] no pensar com o outro e para o outro que o professor pode encontrar as estratégias adequadas a cada tipo de situação e problema enfrentado".

\section{2 - Conhecer as especificidades dos alunos com necessidades educacionais especiais}

Nove autores destacam a necessidade de os professores conhecerem seus alunos, as especificidades das deficiências, suas singularidades, dificuldades e potencialidades.

Melo e Martins (2007, p. 124) afirmam que o professor deve "[...] conhecer as singularidades desse aluno para poder intervir pedagogicamente de forma adequada".

Ao referirem-se aos alunos com paralisia cerebral, especificamente, Reganhan e Braccialli (2008, p. 387) enfatizam que é importante "[...] identificar as necessidades e habilidades do aluno [...] a fim de estabelecer um trabalho educacional eficaz".

Omote et al. (2005, s.p.) ressaltam que os professores devem ter "[...] compreensão das características e necessidades especiais de alunos deficientes".

Ferreira (2006) também destaca que o professor que atende ao perfil inclusivo deve conhecer as características individuais de cada aluno para poder planejar aulas que levem em conta tais condições.

Este conhecimento, no entanto, não deve se limitar ao diagnóstico clínico desses alunos e sim ter a percepção de suas potencialidades educacionais (BEYER, 2005). O conhecimento das características dos alunos com NEE deve ser dar por meio das interações cotidianas, nos momentos de realização das atividades escolares. Para isso, o professor deve estar atento, observando o desempenho acadêmico dos alunos, seu nível de desenvolvimento e a sua forma de interação social nos diferentes contextos da escola. As avaliações dos especialistas, particularmente da área da saúde, devem ser tomadas como complementares (BRASIL, 2002). 
Na perspectiva da educação inclusiva, a avaliação deixa de ter a função classificatória e passa a ter uma função compreensiva sobre processo de aprendizagem do aluno com NEE. Sendo assim, a avaliação educacional que os profissionais da educação, professor da classe comum e professor especializado em educação especial, possam realizar é de fundamental importância para fundamentar o planejamento das ações educacionais adequadas às necessidades educacionais especiais dos alunos.

\section{3 - Conhecer os procedimentos didático-pedagógicos, os funda- mentos da educação e a legislação}

Encontramos em nove textos analisados, referências sobre os saberes didático-pedagógicos, os fundamentos da educação e a legislação educacional.

Segundo Duboc (2005, s. p.), é importante que os professores "[...] detenham sólida fundamentação teórica e prática que Ihes permitam identificar as dificuldades comuns dos alunos".

Com relação à mesma questão, Carvalho (2005, p.33) analisa que os professores devem ter como fundamentos teóricos: "[...] filosofia, metodologia de pesquisa, ciências biológicas, naturais, sociais, psicologia, psico e sociolinguística, história da educação, antropologia, tecnologias a serviço do ensino-aprendizagem, ética, política e estética".

Quanto aos conhecimentos referentes à legislação educacional, Anção (2008, p. 86) destaca que: "há de se considerar a importância da apropriação da legislação pelos profissionais da educação".

Acreditamos que os conhecimentos sobre a legislação e os fundamentos da educação inclusiva possibilitam que os professores analisem criticamente as condições escolares que ainda não estão adequadas a essa perspectiva educacional. Além disso, o conhecimento dos direitos do aluno com NEE, provavelmente, poderia alterar o imobilismo presente em muitas salas de aula, nas quais os professores, diretores e pedagogos reconhecem apenas o direito desse aluno à matrícula na classe comum e desconsideram seus direitos mais importantes, aqueles que garantem o atendimento às suas necessidades educacionais especiais.

sivos

\section{4 - Conhecer pesquisas e relatos que abordam processos inclu-}

Seis autores defendem a importância de os professores conhecerem, por meio de pesquisas e relatos, aspectos reais de processos inclusivos e, sobretudo, os princípios do paradigma educacional inclusivo. 
Dentre eles, citamos Peterson (2006, p. 8) quando afirma que "[...] todos os professores necessitam conhecer pesquisas e práticas eficazes para ensinar todos os alunos com deficiência".

Gomes e Barbosa (2006, p. 88) enfatizam que o conhecimento sobre o processo educacional inclusivo influencia uma posição favorável do professor frente à educação inclusiva.

Com relação a esse aspecto, Omote et al. (2005, s.p.) ressaltam que:

Muitas das decisões a serem tomadas, adotadas para a acolhida positiva e a provisão do imprescindível suporte ao aluno especial, visando o convívio produtivo a toda a classe, podem depender da correta compreensão da proposta da educação inclusiva e das atitudes sociais genuinamente favoráveis à inclusão por parte do professor.

Com base nas observações dos autores, podemos perceber que é mais provável que os professores aceitem uma proposta educacional que eles conheçam os princípios e objetivos, do que quando são levados a colocar em prática um projeto educacional que desconhecem.

\section{5 - Conhecer o processo de desenvolvimento e aprendizagem de pessoas com NEE}

Cinco autores consultados citaram que é importante que os professores conheçam as teorias de desenvolvimento humano para atuarem junto aos alunos com NEE.

Reganhan e Manzini (2009, p. 133) destacam que, para o professor conseguir realizar adaptações curriculares, "[...] é necessário conhecer detalhadamente o desenvolvimento normal (biomecânico, motor e sensorial)".

Rodrigues (2008b, p. 12) também dá destaque para esta questão, observando que é importante que o professor conheça as "[...] características de desenvolvimento e de aprendizagem de alunos com condições não habituais".

Para Pletsch e Braun (2008, s. p.), "[...] é necessário compreender os processos de aprendizagem do aluno, pois só assim deixamos de nos fixar no déficit para favorecer as possibilidades, pois 'esse aluno' aprende, mas de uma forma diferente".

Acrescentamos ao referencial encontrado, as análises de Beyer (2006), já que ele considera imprescindíveis as contribuições da teoria de desenvolvimento humano, defendida por Vygotski, para promover o desenvolvimento do 
pensamento inclusivo. Para ele, "talvez Vygotski tenha sido o primeiro pensador, cujas idéias abordaram conceitos centrais do projeto inclusivo" (p. 11).

Beyer explica que "não há uma pessoa deficiente, porém uma pessoa (como as demais) cujo um dos seus atributos é não ouvir, não ver, não andar, e assim por diante" (2006, p. 9). Neste sentido, as pessoas devem deixar de pensar e de definir a deficiência como atributos individuais do sujeito e devem compreender que:

\begin{abstract}
A criança com necessidades especiais não é uma criança ontologicamente deficiente, porém uma criança como todas as demais, com particularidades definidas na sua aprendizagem. Não é uma criança marcada pelo déficit, porém alguém que reúne uma série de atributos que podem pesar favoravelmente para uma aprendizagem significativa e eficaz (BEYER, 2006, p. 9, grifo do autor).
\end{abstract}

De um modo geral, os autores reforçam a ideia de que, para se promover a inclusão, é necessário que os professores compreendam como se dá o processo de desenvolvimento e aprendizagem dos alunos, considerando as especificidades de sua deficiência.

\title{
inclusiva
}

\section{6 - Conhecer sobre o papel da educação especial na educação}

Dois autores afirmam que é importante que os professores tenham clareza sobre as contribuições da Educação Especial no processo de inclusão de alunos com NEE, especialmente em relação aos conhecimentos desenvolvidos nesta área e aos seus especialistas.

Peterson (2006, p. 6) destaca que, para o atendimento dos alunos com deficiência se dar de forma mais eficaz, "todos os educadores [...] precisariam mudar sua mentalidade e pensar a educação especial como um serviço e não um lugar ou um rótulo".

Rodrigues (2008b) pondera que os professores devem saber qual a relação que a educação inclusiva estabelece com as escolas especiais e compreender que, nestas escolas, foram desenvolvidos conhecimentos que podem ser usados para melhorar a educação de todos os alunos na escola regular.

Gardou e Develay (2005, p. 44) analisam a importância de ir além, que é chegada a hora da área da Educação assumir a educação dos alunos com NEE, reconhecendo a grande contribuição que muitos educadores desenvolveram ao se dedicarem à educação dessas pessoas nos diferentes períodos da história. Para isso, defendem eles que a Educação deve abandonar a ideia de normalidade e as ações derivadas desta perspectiva e perceber que: 
[...] o humano não tem como limite formas, aparências, corpos, vozes e idéias conformistas ou categorias estáticas e encarceradoras. "Como impôr o normal sem idiotice nem crime» (Serres, 1997), quando o humano é variedade, complexidade, plasticidade, improvisação, invenção, flutuação, crise, regulação, movimento?

\section{7- Conhecer as barreiras sociais que dificultam o processo de inclusão dos alunos com necessidades educacionais especiais}

Um dos textos abordou a questão da necessidade de o professor conhecer as barreiras sociais que dificultam a aceitação do aluno deficiente na escola.

Conceição e Krug (2009, p. 241) entendem que "[...] a percepção dos processos que coagem os indivíduos e dificultam a aceitação do aluno com necessidades educacionais especiais" constitui um dos fatores imprescindíveis para a construção dos ideais sobre a escola inclusiva. Aliada a esta percepção, os autores relatam ainda que é necessário que os professores identifiquem os conceitos que a comunidade educacional tem construído sobre os alunos deficientes. À medida que entenderem as contradições e as relações de poder que existem dentro e fora da sala de aula, os professores saberão lidar melhor com os conflitos que possam ocorrer. Conflitos estes que são inerentes à convivência diária entre indivíduos e próprios dos seres humanos, como bem analisaram os autores.

\section{Considerações finais}

Consideramos que os resultados desta pesquisa podem contribuir para subsidiar a organização dos conteúdos a serem contemplados nos cursos de licenciatura que visam à preparação dos graduandos, futuros professores, para atuarem em salas de aula que tenham alunos com NEE. Estes podem ser tomados como base para o desenvolvimento de programas de formação em serviço e/ou continuada, uma vez que os professores, em sua maioria, encontram-se despreparados para atuar junto aos referidos alunos.

Destacamos que o processo de formação de professores é complexo e a obtenção de qualidade está na dependência de múltiplas dimensões. Aqui, analisamos uma dessas dimensões, a que se refere aos saberes conceituais, teóricos e metodológicos, todavia, como bem comenta Rodrigues (2008b), temos outras, relativas ao saber fazer e às atitudes dos professores. Em outras palavras, a formação do professor não deve prescindir dos conhecimentos teóricos relevantes desenvolvidos na área, mas estes não são suficientes, devemos acrescer conhecimentos derivados da experiência direta, obtidos nas situações concretas de sala de aula, os quais visam ao desenvolvimento das habilidades referentes ao saber fazer, à reflexão sobre a prática e sua relação com as teorias estudadas, bem como à reflexão sobre as atitudes dos professores sobre o processo de inclusão de alunos com NEE. 
A literatura especializada também destaca que, para promover a educação inclusiva, os professores não devem ater-se apenas aos conhecimentos provenientes da educação especial e às dimensões técnicas de sua atividade profissional. Além dos conhecimentos e habilidades que todos os professores devem adquirir e desenvolver no exercício da profissão, a capacidade que eles têm de se comprometer com a educação de todos os alunos, com ou sem deficiências, ainda é uma questão fundamental para o sucesso de práticas inclusivas, é um imperativo ético da profissão docente.

\section{Referências}

ALVES, W. F. A formação de professores e as teorias do saber docente: contextos, dúvidas e desafios. Educação e Pesquisa, São Paulo, v. 33, n. 2, p. 236-280, maio/ago. 2007. Disponível em: <<http://www.scielo.br/pdf/ep/v33n2/ a06v33n2.pdf>. Acesso em: 8. set. 2010.

ANÇÂO, C. di B.. Educação inclusiva: análise de textos e contextos. (Dissertação) Mestrado em Educação, Universidade Estadual de Londrina, Londrina, PR, 2008.

ANDRĖ, M. E. D. A. de; MACKENZIE, P. C. A. de A. A profissionalidade do professor formador sob o impacto das reformas e mudanças no mundo contemporâneo. s/d. Disponível em: <<http://www.alb.com.br/anais17/ txtcompletos/conferencias/Marli_Patricia.pdf >. Acesso em: 8.set. 2010>.

BARDIN, L. Análise de conteúdo. 5. ed. Lisboa: Edições 70, 2009. 281p.

BRASIL. Ministério da Educação. Avaliação para identificação das necessidades educacionais especiais. Brasília, DF: MEC/SEESP, 2002. 103 p.

BEYER, H. O. A educação inclusiva: ressignificando conceitos e práticas da educação especial. Inclusão. Rev. da Educ. Esp. Secretaria de Educação Especial. Brasília, DF, v. 2, n. 2, p. 8-12, jul. 2006.

. Inclusão e avaliação na escola: de alunos com necessidades educacionais especiais. Porto Alegre: Mediação, 2005. 128 p.

CARVALHO, R. E. Diversidade como paradigma de ação pedagógica na educação infantil e séries iniciais. Inclusão - Revista da Educação Especial, v.1, n. 1, p. 29-34, out. 2005.

CONCEIÇÃO, V. J. S. da; KRUG, H. N. Formação inicial de professores de educação física frente à uma realidade de inclusão escolar. Revista Educação Especial, v. 22, n. 34, maio/ago. 2009. p. 237-250. Disponível em: <http:// cascavel.ufsm.br/revistas/ojs-2.2.2/index.php/educacaoespecial/article/viewFile/ 276/135>. Acesso em: 12 ago. 2010.

CUNHA, E. R. Os saberes docentes ou saberes dos professores. 2003. Disponível em: <www.nead.unama.br/prof/admprofessor/file_producao.asp?codigo.>. Acesso em: 11 set. 2010. 
DUBOC, M. J. de O. A formação do professor e a inclusão educativa: uma reflexão centrada no aluno surdo. Revista Centro de Educação, Santa Maria, RS, Cadernos, n. 26, 2005. Disponível em: <http://coralx.ufsm.br/revce/>. Acesso em: 21 mar. 2010.

FERREIRA, W. B. Inclusão X exclusão no Brasil: reflexões sobre a formação docente dez anos após Salamanca. In: RODRIGUES, David (Org.). Inclusão e educação: doze olhares sobre a educação inclusiva. São Paulo: Summus, 2006. p. 212-238.

FREITAS, H. C. L. de. Formação de professores no Brasil: 10 anos de embate entre projetos de formação. Educação e Sociedade, Campinas, SP, v. 23, n. 80, p. 136-167, set./2002. Disponível em: <http://www.scielo.br/pdf/es/v23n80/ 12928.pdf $>$. Acesso em: 8. set. 2010.

GARDOU, C.; DEVELAY. M. O que as situações de deficiência e a educação inclusiva "dizem" às ciências da educação. Revista Lusófona de Educação, v. 6, p. 31-45, 2005.

GLAT, R. et al. Formação de professores na educação inclusiva: diretrizes políticas e resultados de pesquisas. 2006. Disponível em: <http:// www.eduinclusivapesquerj.pro.br/livros_artigos/pdf/endipe3.pdf>. Acesso em: 12 mar. 2010.

GOMES, C.; BARBOSA, A. J. G. Inclusão escolar do portador de paralisia cerebral: atitudes de professores do ensino fundamental. Revista Brasileira de Educação Especial , vol.12, no.1 p. 85-100, 2006. Disponível em: <http:// www.scielo.br/pdf/rbee/v. 12n. 1/31986.pdf>. Acesso em: 28. jul. 2010.

MELO, F.R. L. V. de; MARTINS, L. de A. Ramos. Acolhendo e atuando com alunos que apresentam paralisia cerebral na classe regular: a organização da escola. Revista Brasileira de Educação Especial v.13, n.1, p. 111-130, 2007. Disponível em: <http://www.scielo.br/pdf/rbee/v13n1/a08v13n1.pdf>. Acesso em: 2 maio 2010.

NOZI, G. S. Saberes necessários aos professores do ensino regular para promover a inclusão de alunos com necessidades educacionais especiais. (Trabalho de conclusão de curso) - Graduação em Pedagogia, Universidade Estadual de Londrina, Londrina, PR, 2010. 67 p.

NUNES, C. M. F. Saberes docentes e formação de professores: um breve panorama da pesquisa brasileira. Educação \& Sociedade, ano 23, n. 74, abr./ 2001. Disponível em: <http://www.scielo.br/pdf/es/v22n74/a03v2274.pdf>. Acesso em: 9 set. 2010.

OMOTE, S. et al. Mudança de atitudes sociais em relação à inclusão. Paidéia (USP), Ribeirão Preto, SP, v. 15, n. 32, p. 387-398, dez. 2005. Disponível em: <http://sites.ffclrp.usp.br/paideia/artigos/32/07.htm>. Acesso em: 9 ago. 2010. 
PETERSON, P. J. Inclusão nos Estados Unidos: filosofia, implementação e capacitação de professores. Rev. bras. educ. espec., Marília, SP, v. 12, n. 1, abr. 2006. Disponível em: <http://www.scielo.br/pdf/rbee/v12n1/31981.pdf>. Acesso em: 11 mar. 2010.

PLETSCH, M. D. A formação de professores para a educação inclusiva: legislação diretrizes políticas e resultados de pesquisas. Educar em Revista, Curitiba, n. 33, 2009. Disponível em: <http://www.scielo.br/ scielo.php ? script =s ci_art text\&pid = S010440602009000100010\&lng=en\&nrm=iso>. Acesso em: 8 de mar. 2010.

PLETSCH, M. D.; BRAUN, P. A inclusão de pessoas com deficiência mental: um processo em construção. Democratizar, v. 2, n. 2, maio/ago. 2008. Disponível em: <http://www.eduinclusivapesq-uerj.pro.br/livros_artigos/pdf/ defic_mental.pdf>. Acesso em: 12 mar. 2010.

RAMOS, V. de P. Políticas e estratégias de atendimento educacional para alunos com necessidades educacionais especiais no Município do Rio de Janeiro, Brasil suas implicações no desenvolvimento da educação inclusiva em Cabo Verde. Dissertação. (Mestrado em Educação) - Universidade do Estado do Rio de Janeiro, Rio de Janeiro, 2009.

.REGANHAN, W. G.; MANZINI, E. J. Percepção de professores do ensino regular sobre recursos e estratégias para o ensino de alunos com deficiência. Revista Educação Especial, Santa Maria, RS, v. 22, n. 34, p. 127-138, maio/ago. 2009. Disponível em: <http://www.ufsm.br/revistaeducacaoespecial $>$. Acesso em: 7 mar. 2010.

REGANHAN, W. G.; BRACCIALLI, L. M. P. Inserção de alunos com deficiência no ensino regular: perfil da cidade de Marília. Revista Brasileira de Educação Especial, Marília, SP, v. 14, n. 3, dez. 2008. Disponível em: <http:// www.scielo.br/scielo.php?script=sci_arttext\&pid=S141365382008000300005\&lng=pt\&nrm=iso >. Acesso em: 12 mar. 2010.

RODRIGUES, D. Questões preliminares sobre o desenvolvimento de políticas de educação inclusiva. Inclusão - Rev. Edu. Espec., Brasília, DF, v. 4, n. 1, p. 33-40, jan./jun. 2008a. Disponível em: <http://portal.mec.gov.br/seesp/arquivos/ pdf/revinclusao5.pdf>. Acesso em: 12 mar. 2010.

. Desenvolver a educação inclusiva: dimensões do desenvolvimento profissional. Inclusão - Rev. Educ. Espec., Brasília, DF, v. 4, n. 2, p. 7-16, jul./out. 2008b. Disponível em: <http://portal.mec.gov.br/ index.php?option $=$ com_content $\&$ view $=$ article $\& i d=12625 \&$ Itemid $=860>$. Acesso em: 21 mar. 2010.

ROSSETTO, E. Recuperação histórica das políticas de inclusão no ensino superior. 2009. Disponível em: <www.histedbr.fae.unicamp.br/acer_histedbr/ seminario/.../WrKNHCJb.doc>. Acesso em: 25 mar. 2011. 
SALGADO, S. da S. Inclusão e processos de formação. In: SANTOS, M. P.; PAULINO, M. M. (Orgs.). Inclusão em educação: culturas, políticas e práticas. São Paulo: Cortez, 2006. p. 59-68.

SANT'ANA, I. M. Educação inclusiva: concepções de professores e diretores. Psicologia em Estudo, Maringá, PR, v. 10, n. 2, ago./2005. Disponível em: <http://www.scielo.br/pdf/pe/v10n2/v10n2a09.pdf>. Acesso em: 18 mar. 2010.

SAVIANI, D. Escola e democracia. 33. ed. Campinas, SP: Autores Associados, 2000. $94 \mathrm{p}$.

TARDIF, M. Saberes profissionais dos professores e conhecimentos universitários: Elementos para uma epistemologia da prática profissional dos professores e suas conseqüências em relação à formação para o magistério. Revista Brasileira de Educação, n. 13, p. 5-24. jan./fev./mar./abr. 2000. Disponível em: < h t t p : / / w w w a nd re a p e n t e a d o. com / f i le s / tardif_saberes_profissionais_dos_professores.pdf>. Acesso em: 8 set. 2010.

VITALIANO, C. R. Concepções de professores universitários da área de Educação e do ensino regular sobre o processo de integração de alunos especiais e a formação de professores. 2002. Tese (Doutorado em Educação) - Universidade Estadual Paulista. Faculdade de Filosofia e Ciências, Marília.

Análise da necessidade de preparação pedagógica de professores de curso de licenciatura para inclusão de alunos com necessidades especiais. Revista Brasileira de Educação Especial. Marília, SP, v. 13, n. 3, p. 399-414, set./dez. 2007.

(Org.). Formação de professores para inclusão de alunos com necessidades educacionais especiais. Londrina, PR: EDUEL, 2010. 162 p.

\section{Correspondência}

Gislaine Semcovici Nozi - Rua Ibirá, 310, Jardim Alvorada, CEP: 86062-430 - Londrina, Paraná.

E-mail: nozigislaine2@hotmail.com 